\title{
Obtaining and study of the effect of liposomal solution of the follicular chicken eggs' extract on the quality of bread
}

\author{
Viktoriia Bondareva, Oleg Miroshnikov, \\ Oleksii Muratov, Maryna Kolesnik
}

National University of Food Technologies, Kyiv, Ukraine

\section{Keywords: \\ Phosphatidy- \\ lethanolamine \\ Phosphati- \\ dylcholine \\ Yeast \\ Bread \\ Egg}

\section{Article history:}

Received 16.03.2017

Received in revised

form 29.05.2017

Accepted 05.09.2017

\section{Corresponding}

author:

Oleg Miroshnykov

E-mail:

olegmir48@ukr.net

\section{Abstract}

Introduction. The article describes the process of fermentation by means of yeast cells in a lipid liposome solution in alcohol, which containing pure Phosphatidylcholine and the mixture of Phosphatidylethanolamine and Phosphatidylcholine (PE and PC).

Materials and methods. In this work we used methods of microbiological analysis and test bread baking in the laboratory. During the microbiological research we used a nutrient medium (wort), Saccharomizces cerevisiaeyeast cells, the yeast suspension of a pure culture and the liposomal solution. For the study of the effect of liposomal extracts on the quality of bread it was carried out baking of it.

Results and discussions. During the microbiological experiments at 36 hours it was observed the most efficient process of fermentation in liposomal extract which contained $3.24 \mathrm{~g}$ of pure Phosphatidylcholine and mixture of Phosphatidylcholine and Phosphatidylethanolamine. The fermentation process was slowed down in samples that contained less than $2 \mathrm{~g}$ of phospholipids in liposomal solutions. The fermentation process wasn't beginning at the content of phospholipids less than $0.1 \mathrm{~g}$ in liposomal solutions. Because preparation of lipid solution with a mixture of PC and PE has technological and economic advantages in comparison with preparation a solution, which containing of pure FC, then it was used lipid extracts of follicular eggs with the mixture of PC and PE for baking bakery samples. $2.5,5,10,15,20,30 \mathrm{ml}$ of liposomal extract was injected in samples. The obtained samples of bread were analyzed after cooling for 24 hours with the proposed methodological parameters: specific volume, dimensional stability of bread H/D organoleptic evaluation of bread quality, $\mathrm{pH}$.

Conclusions. It was obtained samples with high consumer properties that fully meet quality standards due baking bread using liposomal solutions of lipid alcohol extract.

DOI: $10.24263 / 2310-$

1008-2017-5-1-4 


\section{Introduction}

Liposomes are artificial-generated lipid vesicles, which consist of one or more phospholipid bilayers separated by water phase.

Currently, there are several main ways of obtaining of liposomes: processing by ultrasound of aqueous suspensions of phospholipids, their extrusion and homogenization under high pressure.

Liposomes used as a model of biological membranes. Hereinafter it was found that they can be used as microcontainer which is able to deliver different drugs to different organs and tissues. It can be placed enzymes, hormones, vitamins, antibiotics and bioactive compounds in liposomes.

In the food industry, liposomes are used to encapsulation and controlled release of biologically active components, as well as improving stability and shelf life of sensitive ingredients of food products. Liposomes can be a carrier of antimicrobial agents to protect food products from microbial pollution, nutrients, nutraceuticals, enzymes and food additives for enrichment of food products by relevant ingredients [1]. Currently liposomal solutions are widely used in the dairy and meat processing industries [2-4]. Injection of liposomal forms in foods allows to create a completely new range of products for baby food, nutrition for pregnant women and the elderly, which has prospects of development of food industry [5-9].

Liposomes are widely used in fields of chemistry and biomedicine, pharmaceutics, cosmetology and food production. It caused by certain physicochemical properties of liposomes: they are completely biocompatible in the body of humans and animals, because they obtained from natural phospholipids; they able to include many bioactive substances, including enzymes, hormones, vitamins, antibiotics, immunomodulators, cytostatic agents, pharmacology drugs and others; they provide purposeful transportation and prolonged release of the included substance; substances, included in the liposomes, are more stable, because they isolated by lipid membrane from the negative influences of factors of surrounding environment.

Liposomes are formed from both natural and synthetic phospholipids, as well as from mixtures of phospholipids.

Main substances for generation liposomes are lecithin (Phosphatidylcholine (PC) and Phosphatidylethanolamine (PE)) which obtained from soybeans, rarely from sunflower seeds. However, content of PC and PE at soybeans, it is a main source of production of lecithin from vegetal resources, amounts at most $22-35,5 \%$ from a total amount of the phospholipids, then its content amounts close $72 \%$ in the yolks of chicken eggs. It requires a highly a more vegetal resources than chicken eggs for obtaining equal amounts of PC. Lecithin, which obtained from the chicken eggs, has high bioactive properties, but high commercial price cause limited-use of chicken eggs as sources for receiving of quality lecithin.

Therefore obtaining phospholipids from alternative sources remains actual. One of such alternative sources of the extraction of Phosphatidylcholine and Phosphatidylethanolamine can be follicular chicken eggs. This product unites bioactive properties of the yolks of chicken eggs, a commercial availability of vegetal resources and has a technological advantage - there is absence of a protein native shell, which complicates the process of the extraction of original natural material due receiving of lecithin.

Technologies of obtaining liposomal lipid solutions of follicular chicken eggs in alcohol with PC and mixture of PC+PE content are giving in refs. [10,11]. These allow to establish that liposomal lipid solutions of follicular eggs has economic, technological and 
biological advantages compared with lipid solutions, which obtained from normal chicken eggs or vegetal resources of natural phospholipids, for example, from soybeans or sunflower seeds.

Review of scientific literature has allowed establishing that investigation regarding the making of liposomal lipid solutions of follicular chicken eggs in alcohol and use of them in different branches of industry do not present.

Considering the advantages of liposomal lipid solutions of follicular eggs it may be appropriate to consider a capability of using these solutions in technologies of producing of bakery products to the end its usage as the potential "containers" for the transportation of the bioactive substances for development of new bread products with promotional positive properties.

\section{Materials and methods}

\section{Microbiological study}

Liposomal solutions, which are containing pure Phosphatidylcholine (PC) and mixture of Phosphatidylethanolamine (PE) and phosphatidylcholine (PC), were used for bakery. For this purpose, model samples were prepared from mentioned liposomal solutions of follicular eggs using Saccharomyces cerevisiae yeast.

To do this, yeast Saccharomizces cerevisiae was injected in a nutrient medium (wort $(6-7 \mathrm{ml})$ by way of a yeast suspension $(0.5 \mathrm{ml})$ and formed the initial sample so-called "control" (C). It was injected to control sample liposomal solutions of follicular chicken eggs with different concentrations.

Thus following model samples of liposomal solutions of follicular eggs was prepared (Table 1).

Table 1

\section{Composition of liposomal solutions of follicular chicken eggs}

\begin{tabular}{|c|c|}
\hline Samples & $\begin{array}{l}\text { Solution's compositions } \\
\end{array}$ \\
\hline $\mathrm{C}$ & $\begin{array}{l}\text { Nutrient medium (wort), } 5 \mathrm{ml}+\text { yeast suspension of a pure culture, } \\
0.5 \mathrm{ml}\end{array}$ \\
\hline $2(\mathrm{PC} 0.1 \mathrm{ml})$ & $\begin{array}{l}\text { "C" + } 0.1 \mathrm{ml} \text { of liposomal solution with Phosphatidylcholine (FC) } \\
\text { content }\end{array}$ \\
\hline $3(\mathrm{FC} 2 \mathrm{ml})$ & $\mathrm{C}+2 \mathrm{ml}$ of FC \\
\hline 4 (FC $4 \mathrm{ml})$ & $\mathrm{C}+4 \mathrm{ml}$ of $\mathrm{FC}$ \\
\hline $5(\mathrm{PC} 6 \mathrm{ml})$ & $\mathrm{C}+6 \mathrm{ml}$ of $\mathrm{PC}$ \\
\hline "C" & $\begin{array}{l}\text { Nutrient medium (wort), } 5 \mathrm{ml}+\text { yeast suspension of a pure culture, } \\
0.5 \mathrm{ml}\end{array}$ \\
\hline $2(\mathrm{FE}+\mathrm{FC} 0.1 \mathrm{ml})$ & $\begin{array}{c}\mathrm{C}+0.1 \mathrm{ml} \text { of liposomal solution with content of mixture of } \\
\text { Phosphatidylcholine and Phosphatidylethanolamine }(\mathrm{PC}+\mathrm{PE})\end{array}$ \\
\hline $3(\mathrm{PE}+\mathrm{PC} 2 \mathrm{ml})$ & "C" $+2 \mathrm{ml}$ of $\mathrm{FE}+\mathrm{FC}$ \\
\hline 4 (РЕ+РС 4 мл) & "C" + $4 \mathrm{ml}$ of $\mathrm{FE}+\mathrm{FC}$ \\
\hline 5 (РЕ+РС 6 мл) & "C" + $6 \mathrm{ml}$ of $\mathrm{PE}+\mathrm{PC}$ \\
\hline
\end{tabular}

The technology of obtaining lipid extracts of follicular chicken eggs in alcohol with the contents of FC and mixture of FC+PE is given in refs. [10,11]. It was considered the 
advantages of the lipid extract, which contained the mixture of Phosphatidylcholine and Phosphatidylethanolamine. It was proved advantages of obtaining lipid extracts of follicular chicken eggs over other natural plant and animal sources of phospholipids.

\section{Laboratory baking of bread samples}

After conducting microbiological studies to determine the impact of the most effective concentration liquid on the fermentation process was carried out baking bakery samples.

The preparation of the dough for bread samples was carried out without sponge, the matter of which is as follows. For kneading yeast was diluted with water with a temperature of $30-35^{\circ} \mathrm{C}$. Margarine dosed out according to the calculated amount in the melted state. Sugar and salt were added to components in the aqueous solution. Liposomal extract was introduced into components according to the recipe (table 2).

Table 2

Formulation of investigated samples with the addition of liposome extract of follicular chicken eggs

\begin{tabular}{|l|c|c|c|c|c|c|c|c|}
\hline \multirow{2}{*}{ Raw materials } & \multicolumn{7}{|c|}{ Samples of bakery products } \\
\cline { 2 - 10 } & "C" & 2 & 3 & 4 & 5 & 6 & 7 & 8 \\
\hline Flour (g) & 280 & 280 & 300 & 300 & 300 & 300 & 300 & 300 \\
\hline Yeast (g) & 5.6 & 5.6 & 5.6 & 5.6 & 5.6 & 5.6 & 5.6 & 5.6 \\
\hline Salt (g) & 4.2 & 4.2 & 4.2 & 4.2 & 4.2 & 4.2 & 4.2 & 4.2 \\
\hline Sugar (g) & 28 & 28 & 28 & 28 & 28 & 28 & 28 & 28 \\
\hline Margarine (g) & 22.4 & 22.4 & 22.4 & 22.4 & 22.4 & 22.4 & 22.4 & 22.4 \\
\hline Chicken eggs (g) & - & 5.6 & - & - & - & - & - & - \\
\hline Water (ml) & 168 & 162.4 & 145.3 & 143.0 & 138 & 133 & 128 & 118 \\
\hline $\begin{array}{l}\text { Liposomal } \\
\text { extract FC+PE } \\
\text { (ml) }\end{array}$ & - & - & 2.5 & 5.0 & 10.0 & 15.0 & 20.0 & 30.0 \\
\hline $\begin{array}{l}\text { Liposomal } \\
\text { extract FC+PE, } \\
(\%)\end{array}$ & - & - & 0.49 & 0.98 & 1.97 & 2.95 & 3.94 & 5.90 \\
\hline Total weight (g) & & & & & & & & \\
\hline
\end{tabular}

It was used the straight dough method due cooking. The required amount of water was weighed in capacity for dough kneading, then it was added a prepared yeast, salt, sugar, margarine and flour. Components were thoroughly mixed until a homogeneous consistency of the dough in laboratory dough kneading machine LT-900.

Fermentation of dough was carried out in the thermostat at the temperature $t=37-40^{\circ} \mathrm{C}$ and relative humidity $\varphi=78-80 \%$ for 1.5 hours. Then the dough was weighed, divided into pieces according to the calculated weight of formed and hearth dough's samples that were stood in the thermostat at $\mathrm{t}=37-40{ }^{\circ} \mathrm{C}$ and $\varphi=78-80 \%$. End-proofing was determined organoleptically as a test and the mind blanks. Bread was baked in the laboratory oven $\mathrm{ESh}-3$ at $\mathrm{t}=200-220{ }^{\circ} \mathrm{C}$.

The quality of the resulting bread samples after cooling for 24 hours was analyzed for the following parameters: specific volume (Figure 1), dimensional stability of hearth bread, H/D (Figure 2), organoleptic evaluation of bread quality (table 3), a measure of the acidity (Figure 3). 


\section{Results and discussions}

Biochemical and microbiological processes, which were occurred in dough, were conditioned to vital functions of microorganisms and the activation of fermentation's systems. At that substances are accumulated in dough which participates in formation of quality of finished products.

It was investigated the activity of the main microflora of wheat dough, this is yeast Saccharomizces cerevisiae, at environment of investigated liposomal solutions of follicular eggs to assess the possibility of using of model samples of these solutions in the recipe of bakery products.

Activity of fermentation process was investigated by microbiological method in model of sample solutions at $30{ }^{\circ} \mathrm{C}$. It was established that the highest activity of fermentative microflora was observed due 36 hours in samples \# 3, \#4, which contains $2 \mathrm{ml}$ and $4 \mathrm{ml}$ of pure Phosphatidylcholine and mixture of Phosphatidylcholine and Phosphatidylethanolamine, respectively (contents of phospholipids is 1.62 and $3.24 \mathrm{~g}$, respectively). The fermentation process starts after 42 hours without the usage of liposomal solutions. Fermentation was not started at a concentration $0.1 \mathrm{ml}$ of liposomal solutions (the content of phospholipids was less than $0.1 \mathrm{~g}$; sample \# 2). The fermentation process was slowed down in sample \# 5, that was contained $6 \mathrm{ml}$ of liposomal solution (the content of phospholipids was $4.86 \mathrm{~g}$ ).

It was mentioned that lipid solutions with the mixture of PC and PE has technological advantages in comparison with samples, which were contained pure PC, then it was used lipid extracts of follicular chicken eggs with PC and PE for baking bakery samples. 2.5, 5, $10,15,20,30 \mathrm{ml}$ of liposomal extract was injected in samples. Analysis of organoleptic indicators of quality of finished bakery products is presented in Table 3 .

The results show that the usage of liposomal solutions of follicular eggs allows obtaining products without foreign tastes and odors. It was obtained products at injecting $2.5 \mathrm{ml}$ and $5 \mathrm{ml}$ of liposomal solutions (samples \# 3 and 4) in investigated samples that are not inferior to the control samples by the organoleptic characteristics. However, it was defined deterioration of the crust's color of products in samples \# 5, 6, 7, 8 with increasing content of liposomal solution of follicular eggs and the formation of thick-walled crumb structure. This is possible due prominent influence of alcohol component of these model solutions of follicular eggs on activity of enzyme system of the dough, the state of proteins and yeast.

It was investigated a specific volume of products and their dimensional stability (Figure 1).

Results are showed that the usage of model samples \# 3 and 4 allows improving the specific volume of products with comparison to both the control and product with the introduction of eggs. This is conditioned of emulsifying properties of utilized liposomal solutions that also promote to improve of the dimensional stability of products and the formation of a thin-walled structure of the products' porosity.

It was marked deterioration both the specific volume of products and their dimensional stability in samples of bread \# 5, 6, 7, 8. The cause of this influence of the increasing of the concentration of alcohol in the studied liposomal lipid solutions, which does not allow to sufficient swell of fibrin proteins of dough and gain a good elasticity of dough. Dough structure was too strengthened then it is deteriorated the dimensional stability of the products. This causes the formation of thick-welled porosity of the products' crumb. Usage of these model solutions suppresses the carrying biochemical and microbiological processes in the dough, that reduces the accumulation of the substances in the dough that forming the taste properties of products and its acidity, especially. This is confirmed by the data in Figure 1,2. Acidity of the finished products was reduced in samples \# 5, 6, 7, 8 (Figure 3). 
Table 3

Organoleptic quality assessment of bread's samples

\begin{tabular}{|c|c|c|c|c|c|c|c|c|c|c|}
\hline \multicolumn{11}{|c|}{ The appearance of the bread } \\
\hline \multirow{2}{*}{$\begin{array}{c}\text { Characteristics } \\
\text { of bread }\end{array}$} & \multirow[t]{2}{*}{ Form of bread } & \multicolumn{9}{|c|}{ The samples of bread } \\
\hline & & "C" & 2 & 3 & 4 & 5 & 6 & & 7 & 8 \\
\hline \multirow[t]{2}{*}{ Form } & hearth & \multicolumn{4}{|c|}{ Regular } & \multicolumn{5}{|c|}{ wrong } \\
\hline & pan & \multicolumn{4}{|c|}{ Regular } & \multicolumn{5}{|c|}{ wrong } \\
\hline \multirow{2}{*}{$\begin{array}{l}\text { The surface of } \\
\text { the crust }\end{array}$} & hearth & \multicolumn{4}{|c|}{ smooth crust } & \multicolumn{5}{|c|}{ uneven } \\
\hline & pan & \multicolumn{4}{|c|}{ smooth crust } & \multicolumn{5}{|c|}{ uneven } \\
\hline \multicolumn{11}{|c|}{ Crust color } \\
\hline \multirow{2}{*}{$\begin{array}{c}\text { Characteristics } \\
\text { of bread }\end{array}$} & \multirow[t]{2}{*}{ Form of bread } & \multicolumn{9}{|c|}{ The samples of bread } \\
\hline & & "C" 122 & 2 & & 4 & 5 & 6 & 7 & & 8 \\
\hline Crust color & hearth & \multirow[t]{2}{*}{$\begin{array}{c}\text { dark } \\
\text { brown }\end{array}$} & \multirow{2}{*}{\multicolumn{2}{|c|}{ brown }} & $\begin{array}{l}\text { dark } \\
\text { rown }\end{array}$ & \multicolumn{3}{|c|}{ lightbrown } & & pale \\
\hline Crust color & pan & & & & rown & & bro & Wn & & pale \\
\hline & & & The & Imbs: & & & & & & \\
\hline Characteristics & Form of bread & & & & The sa & ples & brea & & & \\
\hline of bread & & "C" & 2 & 3 & 4 & 5 & & 6 & 7 & 8 \\
\hline Color & hearth & & & & & & & & & \\
\hline & pan & & & & & & & & & \\
\hline The color's & hearth & & & & form & & & & & Irregular \\
\hline smoothness & pan & & & & form & & & & & \\
\hline Elasticity & hearth & & & & & mid & & & $\mathrm{bac}$ & \\
\hline & pan & & & & & $\mathrm{mid}$ & & & $\mathrm{bac}$ & \\
\hline & & & rosit & cru & & & & & & \\
\hline Characteristics & Form of bread & & & & The sa & ples & brea & & & \\
\hline of bread & & "C" & 2 & 3 & 4 & . & & 6 & 7 & 8 \\
\hline Size of pores & hearth & & & Aver & & & & & sma & \\
\hline & pan & & & Aver & & & & & sma & \\
\hline Uniformity of & hearth & & & Jnife & & & & & unev & ven \\
\hline pores & pan & & & Jnife & & & & & unev & ven \\
\hline The thickness of & hearth & & & Thi & & & & & ick-w & valled \\
\hline the pore walls & pan & & & Thi & & & & & ick-w & valled \\
\hline & & & & & & & & & & \\
\hline Characteristics & Form of bread & & & & samp & of $b$ & & & & \\
\hline of bread & & "C" & 2 & 3 & 4 & 5 & 6 & & 7 & 8 \\
\hline Taste & hearth & & norm & typic & bread & ithou & forei & ign t: & astes & \\
\hline Taste & pan & & & & & & & & & \\
\hline & & Caki & ng du & g ch & ing & & & & & \\
\hline Characteristics & Form of bread & & & & The sa & ples & brea & & & \\
\hline of bread & & "C" & 2 & 3 & 4 & & & 6 & 7 & \begin{tabular}{l|l|} 
& 8 \\
\end{tabular} \\
\hline Caking & hearth & & & $\mathrm{Ocal}$ & & & & the & prese & ence of \\
\hline Caking & pan & & & $\mathrm{ocal}$ & & & & the & prese & ence of \\
\hline & & The fr: & agilit & f the & umb & & & & & \\
\hline Characteristics & form of bread & & & & samp & of $b$ & & & & \\
\hline of bread & & "C" & 2 & 3 & 4 & 5 & 6 & & 7 & 8 \\
\hline Fragility & hearth & & & & No fr & ility & & & & \\
\hline Fragility & pan & & & & No fr & ility & & & & \\
\hline
\end{tabular}




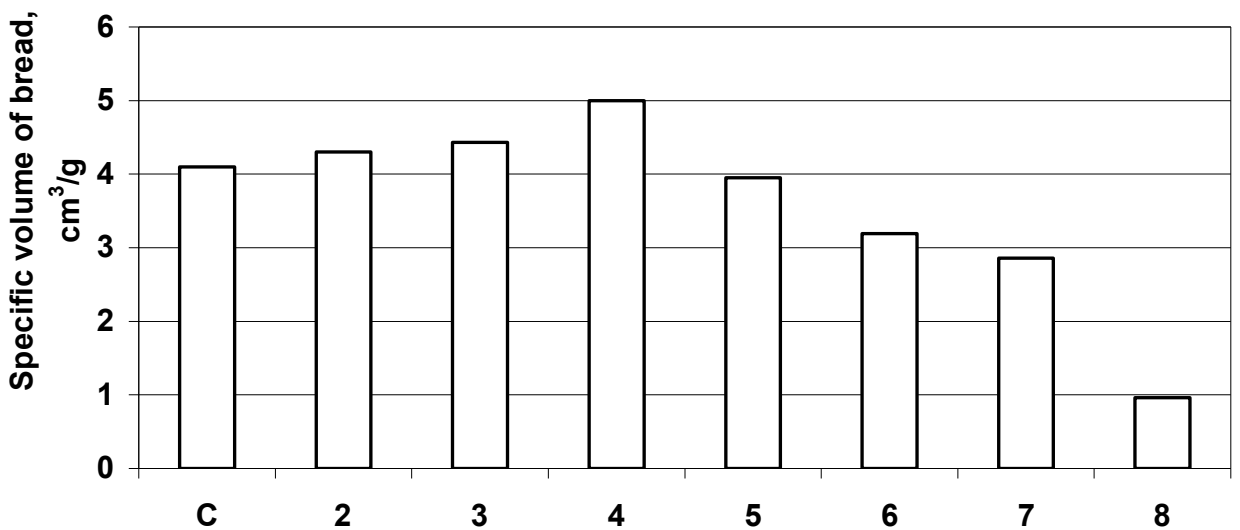

Figure 1. Specific volume of bread

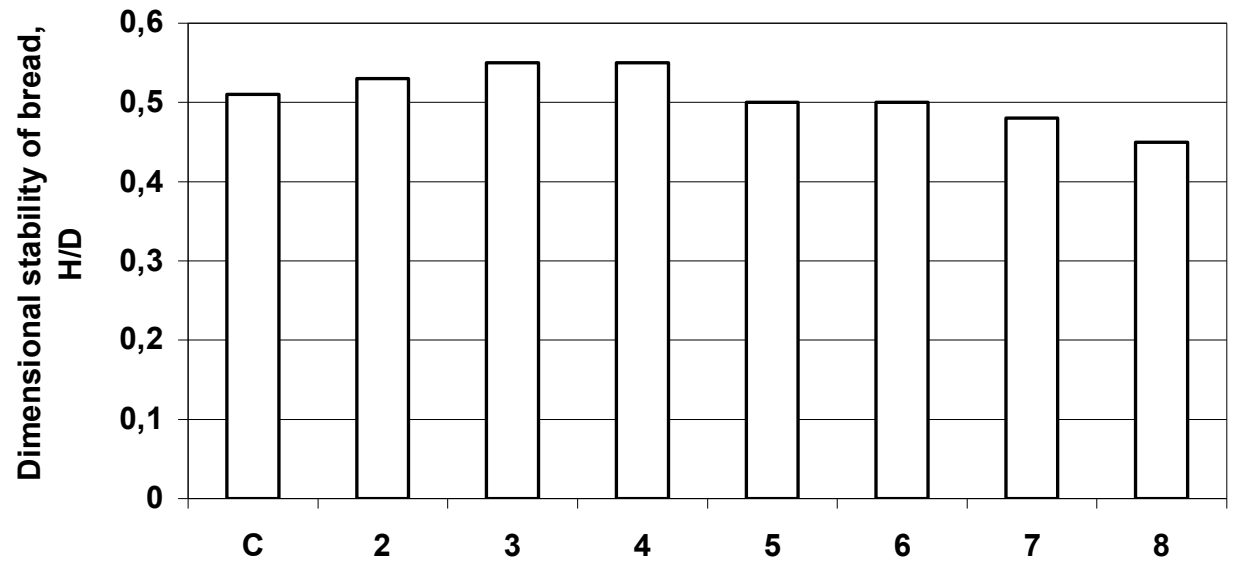

Figure 2. Dimensional stability of bread

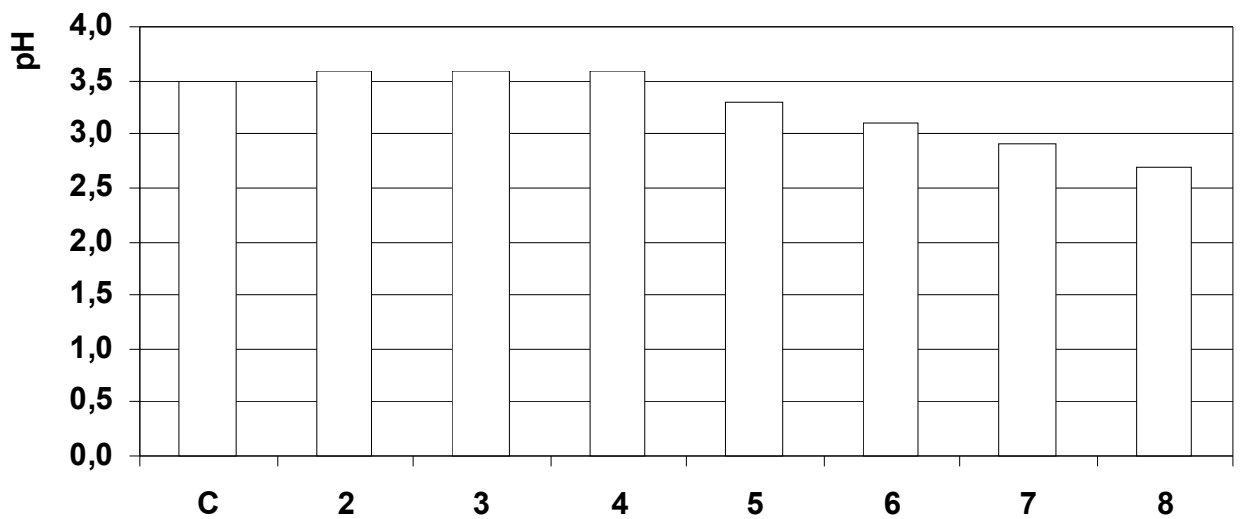

Figure 3. The pH of the wheat bread of the highest grade 


\section{Conclusions}

1. When conducting microbiological experiments the most effective fermentation process was observed at $4 \mathrm{ml}$ of liposomal solutions (the amount of phospholipids is $3.24 \mathrm{~g}$ ), which were contained pure Phosphatidylcholine and the mixture of Phosphatidylcholine and Phosphatidylethanolamine.

2. Sufficient quality of bread was obtained during adding $2.5 \mathrm{ml}(0.49 \%$ from total mass, sample \# 3) and $5 \mathrm{ml}$ (0.98\% from total mass, sample \# 4) of liposomal solutions with the mixture of PC and PE (phospholipid's content is $2.03 \mathrm{~g}$ and $4.05 \mathrm{~g}$, respectively, in $508.2 \mathrm{~g}$ of dough). It was received products at these dosages with good organoleptic indicators of the quality and the volume.

3. Introduction liposomal forms in food products allows to create a completely new product assortments, then the usage of liposomal solutions is promising direction in the food industry.

\section{References}

1. Momin J.K., Joshi B. (2015), Nanotechnology in Foods / Nanotechnology in Food and Agriculture, Springer International Publishing, Switzerland.

2. Tikhomirova N.A. (2008), Nanotechnology in the processing of raw milk, Dairy industry, 4, pp. 68-70.

3. Prosekov A.Yu., Glebova S.Yu., Razumnikova I.S. (2008), Milk protein as a nanoparticle with desired properties, Dairy industry, 4, pp. 71-72.

4. Snezhko A.G., Fedotova A.V. (2008), The use of nanotechnology for the packaging of meat products, Meat Industry, 2, pp. 22-24.

5. Kochetkova A.A., Vasil'yeva S.V. (2009), The phospholipids in the composition of functional food products, Abstracts of X Russian scientific-practical conference "The Plant's lecithin: production, utilization, standardization", Saint-Petersburg, pp. 55-56.

6. Doronin A.F., Shenderov B.A. (2002), Functional food, Grant, Moscow.; [in Russian]

7. Tutel'yan V.A., Kon' I.A. (2004), Guide for child nutrition, Medical information agency, Moscow.

8. Yudina S.B. (2008), Technology of functional foods, DeLi Print, Moscow.

9. Tutel'yan V.A., Sukhanov B.P., Avstrievskihk A.N. (1999), Dietary supplements in human nutrition, Scientific and technical literature publishing, Tomsk.

10. Bondareva V., Mank V., Miroshnikov O. (2014), Determination of phospholipids and protein content in lipid extract obtained from the alcohol solution of follicular hen eggs, Scientific Works of NUFT, 20(5), pp. 199-204.

11. Bondareva V., Mank V., Miroshnikov O. (2015), Separation of liposomes from phospholipid alcohol extract of follicular chicken eggs and definition of their characteristics, Scientific Works of NUFT, 21(6), pp. 220-225. 